\title{
Deteksi kavitasi menggunakan linear discriminant analysis pada pompa sentrifugal
}

\author{
Berli Paripurna Kamiel ${ }^{*}$, Yusuf Ahmad ${ }^{2}$, Krisdiyanto ${ }^{3}$ \\ 1,3Jurusan Teknik Mesin, Fakultas Teknik, Universitas Muhammadiyah Yogyakarta \\ ${ }^{2}$ Prodi Sarjana Teknik Mesin, Fakultas Teknik, Universitas Muhammadiyah Yogyakarta \\ Kampus Terpadu UMY, JI. Brawijaya, Kasihan, Bantul, Yogyakarta, Indonesia 55183 \\ *Corresponding author: berlikamiel@umy.ac.id,
}

\begin{abstract}
Cavitation is a phenomenon that often occurs in the centrifugal pumps. The impact of cavitation is a decrease in pump performance which will affect the ongoing production process in the industries. It is important to have a method to detect the phenomenon of cavitation early. The vibration signal is a parameter that is often used in detecting cavitation or other faulty components. One of the methods is based on the pattern recognition i.e. machine learning. Linear Discriminant Analysis (LDA) is a machine learning algorithm that has the advantage of reducing the parameters used into low dimensions without reducing the accuracy of their classification. The study proposes LDA to classify normal conditions, initial cavitation, intermediate cavitation and severe cavitation. The recording of the vibration signal is taken using the an accelerometer mounted on the inlet of the centrifugal pump. The vibration signal is then extracted using 10 statistic parameters of time domain as the LDA feature selection, namely mean, RMS, standard deviation, kurtosis, skewness, crest factor, clearance factor, shape factor, variance and peak value. The results shows that the LDA classifier can detect and classify cavitation conditions with an accuracy rate of $98.8 \%$ on training and $99.6 \%$ on testing. The shape factor, kurtosis, skewness and RMS parameters are a combination of parameters that have a large contribution to the classifier to detect and classify cavitation conditions.
\end{abstract}

Keywords: Linear Discriminant Analysis (LDA), cavitation, centrifugal pump, statistical parameter

\begin{abstract}
Abstrak
Kavitasi merupakan fenomena yang sering terjadi pada pompa sentrifugal. Dampak yang ditimbulkan dari kavitasi yaitu turunnya performa pompa yang akan mempengaruhi proses produksi yang sedang berlangsung pada suatu pabrik. Maka, dibutuhkan suatu metode untuk mendeteksi dini fenomena kavitasi. Sinyal getaran merupakan parameter yang sering digunakan dalam melakukan deteksi kavitasi ataupun kerusakan mesin lainnya. Salah satu metode yang digunakan dalam menganalisis suatu sinyal getaran adalah metode pengenalan pola (machine learning) dengan menggunakan algoritma tertentu. Linear Discriminant Analysis (LDA) merupakan salah satu algoritma machine learning yang memiliki keunggulan mereduksi parameter yang digunakan kedalam dimensi yang rendah tanpa mengurangi akurasi klasifikasinya. Penelitian ini menggunakan LDA untuk mengklasifikasi kondisi normal, kavitasi awal, kavitasi menengah dan kavitasi lanjut. Perekaman sinyal getaran dilakukan dengan menggunakan sebuah accelerometer yang diletakkan pada sisi inlet pompa. Selanjutnya data sinyal getaran diekstraksi dengan menggunakan 10 parameter statistik domain waktu sebagai feature selection LDA yaitu mean, RMS, standar deviasi, kurtosis, skewness, crest factor, clearance factor, shape factor, variance dan peak value. Hasil yang didapatkan bahwa classfier LDA dapat mendeteksi dan mengklasifikasi kondisi kavitasi dengan tingkat akurasi $98,8 \%$ pada training dan $99,6 \%$ pada testing. Parameter shape factor, kurtosis,
\end{abstract}


skewness dan RMS merupakan kombinasi parameter yang memiliki kontribusi besar dalam classifier untuk mendeteksi dan mengklasifikasi kondisi kavitasi.

Kata kunci: Linear Discriminant Analysis (LDA), kavitasi, pompa sentrifugal, parameter statistik

\section{Pendahuluan}

Pompa sentrifugal merupakan jenis pompa yang sering digunakan dalam dunia industri. Permasalahan yang sering terjadi pada pompa sentrifugal adalah kavitasi [1]. Dampak dari kavitasi pada pompa sentrifugal adalah penurunan kinerja dan bahkan kegagalan sehingga dapat menyebabkan terganggunya proses produksi.

Penelitian yang telah dilakukan banyak menggunakan sinyal getaran untuk mendeteksi kerusakan komponen mesin ataupun kavitasi pada pompa sentrifugal. Kotb \& Abdulaziz [2] melakukan penelitian tentang deteksi kavitasi menggunakan analisis akuistik dan spektrum getaran dengan variabel kecepatan pompa. Luo et al. [3] menyelidiki karakteristik parameter statistik getaran pada pompa sentrifugal. Tobi \& Sabari [4] menerapkan deteksi kavitasi menggunakan metode domain waktu pada pompa sentrifugal. Kamiel \& Ramadhan [5] menyimpulkan pengaruh kecepatan pompa terhadap sensitifitas parameter statistik domain waktu untuk mendeteksi kavitasi. Tobi et al. [6] melakukan diagnosis lima kerusakan (misalignment, looseness, imbalance, cacat bearing, dan cacat impeller) dan kavitasi pada pompa sentrifugal menggunakan spektrum getaran.

Penelitian-penelitian tersebut pada umumnya menggunakan analisis getaran berbasis domain waktu atau spektrum. Akurasi deteksi kavitasi berbasis domain waktu sangat tergantung pada jumlah dan jenis parameter statistik yang diekstrak. Jumlah dan jenis parameter tersebut sangat bervariasi tergantung pada obyek yang dideteksi dan tidak tersedia aturan baku dalam proses memilihnya [7]. Hal ini berpotensi menimbulkan kesulitan dalam aplikasi di lapangan. Sedangkan analisis berbasis spektrum kurang efektif dalam mendeteksi kavitasi karena fast fourier transform (FFT) mengasumsikan bahwa konten frekuensi sebuah sinyal adalah konstan. Sedangkan kavitasi menghasilkan konten frekuensi yang bervariasi terhadap waktu [6]. Akibatnya spektrum yang dihasilkan sulit dibaca dan dianalisis. Kesulitan lainnya adalah pembacaan spektrum membutuhkan seorang ahli yang berpengalaman untuk memutuskan apakah kavitasi terjadi atau tidak. Dibutuhkan pendekatan baru untuk mendeteksi kavitasi pompa dengan mudah dan efektif. Penelitian ini mengusulkan metode pengenalan pola yang dapat mengklasifikasi kondisi pompa secara langsung.

Metode pengenalan pola (machine learning) merupakan salah satu cabang artificial intelligent yang bertujuan untuk klasifikasi ataupun clustering [8]. Salah satunya adalah Linear Discriminant Analysis (LDA). Classifier ini mempunyai keunggulan yaitu dapat mereduksi parameter kedalam dimensi yang rendah sekaligus melakukan klasifikasi tanpa mengurangi hasil akurasinya [9]. Metode ini sudah banyak digunakan oleh peneliti sebelumnya untuk mendeteksi suatu kerusakan pada mesin dan akurat dalam mengklasifikasi kerusakan tesebut. Jakovljevic et al. [9] menggunakan LDA untuk mendeteksi kerusakan rotor bar pada motor induksi. Haddad \& Strangas [10] menggunakan LDA untuk mendeteksi kerusakan pada Permanent Magnet Synchronous Machine (PMSM). Mbo'o \& Hameyer [11] menggunakan LDA untuk mendeteksi kerusakan pada cylindrical bearing.

Namun demikian tidak ditemukan aplikasi LDA untuk mendeteksi terjadinya kavitasi. Oleh kerena itu, penelitian ini mengusulkan LDA untuk mendeteksi kavitasi pada pompa sentrifugal. LDA dalam melakukan klasifikasi menggunakan 
input berupa parameter statistik yang jumlah dan jenisnya sangat bervariasi dan tergantung pada obyek yang dideteksi. Penelitian ini juga menyelidiki dan menyeleksi parameter statistik menggunakan metode binomial coefficient untuk menentukan parameter yang berkontribusi besar terhadap akurasi classifier dalam mendeteksi dan mengklasifikasi kondisi pompa.

\section{Tinjauan Pustaka}

\section{Linear Discriminant Analysis}

LDA merupakan salah satu supervised learning yang dikembangkan oleh R. A. Fisher pada tahun 1936. Classifier ini menentukan kombinasi karakteristik linear yang menggambarkan dua kelas atau lebih. LDA dikembangkan untuk mentransformasikan suatu parameter ke ruang dimensi rendah dengan memaksimalkan rasio varian antar kelas dan meminimalkan rasio varian dalam kelas, sehingga menjamin pemisakan kelas yang dilakukan secara maksimum [12]. Proses transformasi yang dilakukan oleh LDA sebagai berikut,

Langkah awal, menghitung separabilitas antar beda kelas (varian antar kelas) menggunakan Pers. 1.

$$
S_{B}=\sum_{i=1}^{c} n_{i}\left(\mu_{i}-\mu\right)\left(\mu_{i}-\mu\right)^{T}
$$

Dimana $c$ adalah kelas, $n_{i}$ adalah jumlah sampel dari kelas i, $\mu_{i}$ adalah rata-rata kelas $\mathrm{i}$, dan $\mu$ adalah rata-rata keselurahan kelas.

Selanjutnya, menghitung jarak antara rata-rata dengan sampel dari tiap kelas (varian dalam kelas) menggunakan Pers. 2.

$$
S_{W}=\sum_{i=1}^{c} \sum_{j=1}^{n_{i}}\left(x_{j}^{i}-\mu_{i}\right)\left(x_{j}^{i}-\mu_{i}\right)^{T}
$$

Dimana $x_{j}^{i}$ adalah sampel $\mathrm{j}$ yang berada dikelas i.

Merekonstruksi ruang dimensi rendah dengan menggunakan Pers. 3 yang disebut juga sebagai Fisher's criterion.

$$
J(W)=\arg \max \frac{W^{T} S_{B} W}{W^{T} S_{W} W}
$$

Pers. 3 bisa diformulasikan ulang jika $S_{W}$ adalah matriks non-singular dengan menghitung nilai eigen dan eigen vektornya. Hasil formulasi tersebut bisa dilihat pada Pers. 4.

$$
S_{W} W=\lambda S_{B} W
$$

Dengan $W$ adalah transformasi matriks dan $\lambda$ adalah nilai eigen dari transformasi matriks.

Nilai eigen merupakan kekuatan dari vektor eigen. Kekuatan vektor eigen tersebut mencerminkan kemampuan transformasi LDA untuk membedakan antar kelas. Dengan demikian, vektor eigen dengan nilai eigen tertinggi yang digunakan untuk membangun ruang dimensi rendah, sedangkan vektor eigen lainnya bisa diabaikan. Gambar 1 merupakan ilustrasi LDA dalam mengklasifikasi suatu kelas.

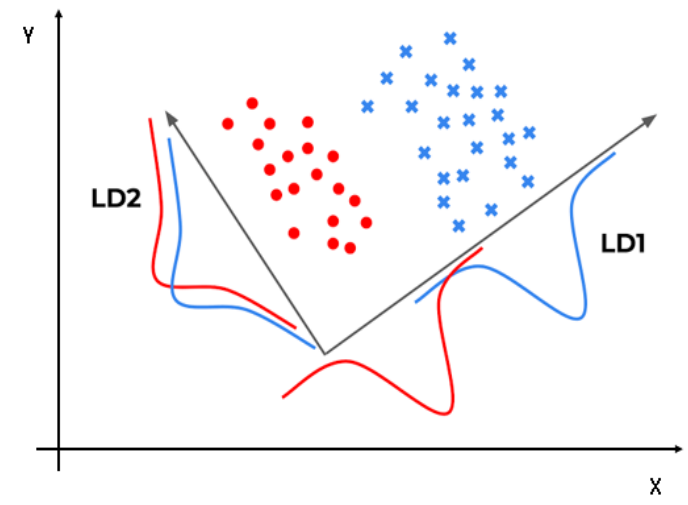

Gambar 1. Ilustrasi LDA

\section{Metode Penelitian}

Penelitian ini menggunakan alat uji simulasi kavitasi yang tersusun berdasarkan skema yang ditunjukkan pada Gambar 2 . Alat uji tersebut terdiri dari pompa sentrifugal, tangki vakum, kompresor vakum, sistem perpipaan, alat ukur tekanan, flowmeter dan katup. Penelitian ini menggunakan 4 macam variasi kondisi yaitu kondisi normal, kavitasi awal, kavitasi menengah dan kavitasi lanjut. Pengaturan kondisi tersebut dengan cara mengatur tekanan udara pada tangki vakum menggunakan kompresor vakum dan 
mengamati pembentukan gelembung kavitasi yang terjadi pada bagian inlet pompa yang transparan. Kondisi normal didapatkan pada tekanan $0 \mathrm{cmHg}$, kavitasi awal $-10 \mathrm{cmHg}$, kavitasi menengah -20 $\mathrm{cmHg}$ dan kavitasi lanjut $-28 \mathrm{cmHg}$. Visualisasi pembentukan gelembung kavitasi dapat dilihat pada Gambar 3.

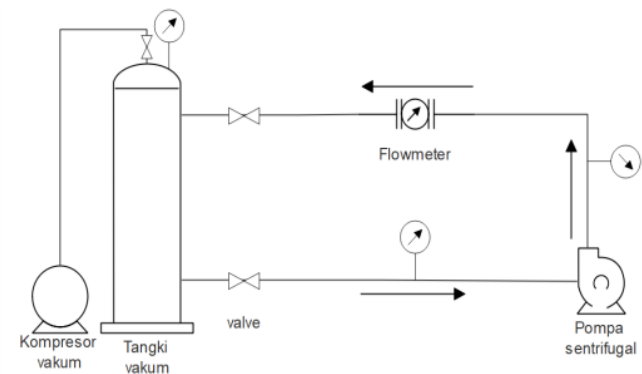

Gambar 2. Alat uji simulasi kavitasi dan arah alirannya

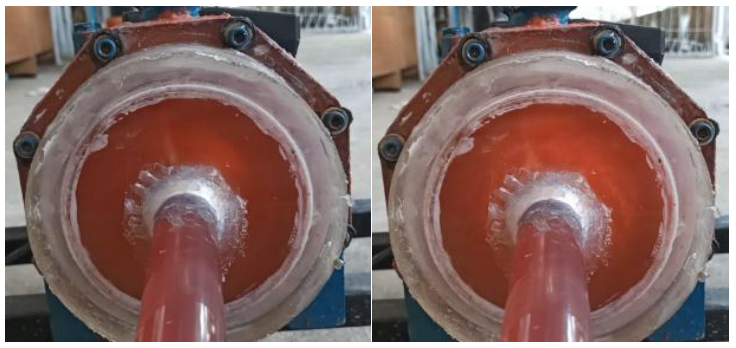

(a)

(b)

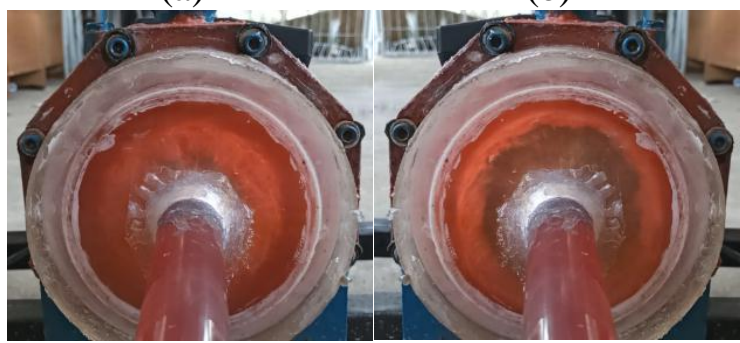

(c)

(d)

Gambar 3. Visualisasi kondisi pompa (a) normal, (b) kavitasi awal, (c) kavitasi menengah, dan (d) kavitasi lanjut

Perekaman sinyal getaran menggunakan sensor accelerometer dari Bruel \& Kjaer tipe 4507 B yang diletakkan pada rumah volute pompa pada yang merekam arah aksial. Sedangkan, modul data akuisisi yang digunakan yaitu National Insturment NI 9234 dengan kecepatan sampling rate $25600 \mathrm{~Hz}$ dan waktu perekaman yaitu 8 detik. Hasil perekaman adalah sebanyak 500 set dari tiap variasi kondisi sehingga total berjumlah 2000 set data. Selanjutnya data set diekstraksi menggunakan parameter statistik. Hasil ekstraksi tersebut dibagi menjadi 2 bagian yaitu 1500 data training untuk membentuk dan melatih classifier dan 500 data testing untuk menguji tingkat akurasi classifier tersebut. Selanjutnya, penelitian ini mencari parameter yang berpengaruh dalam classifier LDA dengan metode binomial coefficient. Gambar 4 merupakan alur pengolahan sinyal getaran.

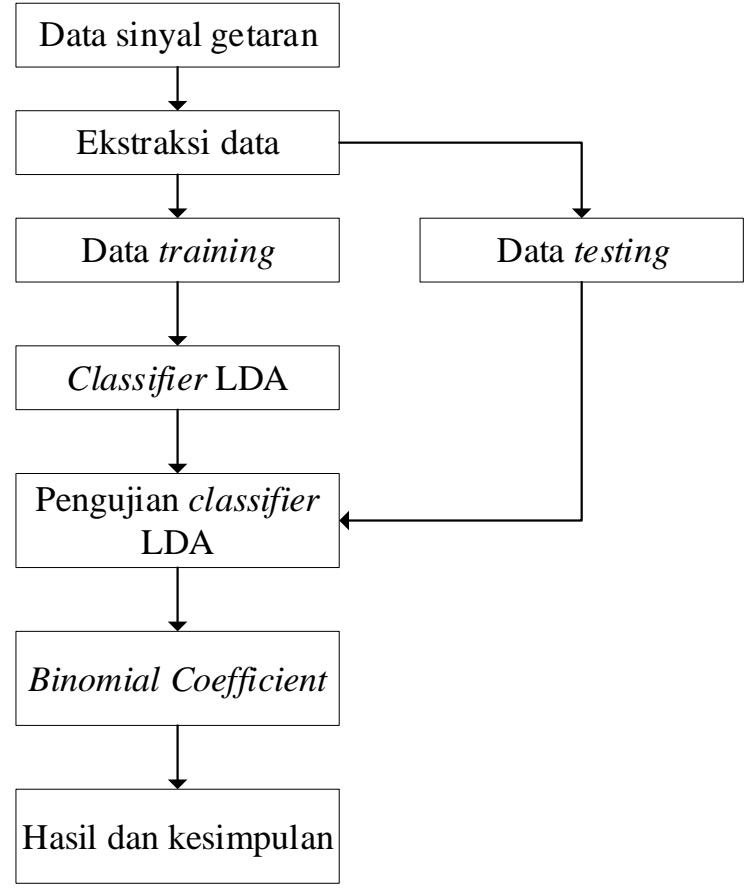

Gambar 4. Skema pengolahan sinyal getaran

\section{Classifier LDA}

Penelitian ini menggunakan parameter statistik domain waktu dalam mengekstraksi sinyal getaran. Parameter statistik tersebut dipilih berdasarkan gabungan parameter yang pernah digunakan oleh Luo et al. [3], Tobi \& Sabari [4], Kamiel \& Ramadhan [5], Jakovjevic et al. [9], dan Mbo'o \& Hameyer [11]. Parameter yang digunakan pada penelitian ini adalah mean, standar deviasi, Root Mean Square (RMS), kurtosis, skewness, crest factor, clearance factor, shape factor, variance dan peak value.

\section{Hasil dan Pembahasan}

Gambar 5 merupakan contoh hasil distribusi nilai ekstraksi parameter mean dan RMS. Jika dilihat secara visual parameter 
mean tidak dapat membedakan 4 variasi kondisi pompa. Hal ini dikarenakan 50\% data hasil ekstraksi parameter tersebut dari masing-masing variasi kondisi, terletak pada posisi yang cenderung sejajar pada grafik boxplot. Sedangkan parameter RMS dapat membedakan kondisi normal karena terlihat pada kondisi normal $50 \%$ data hasil ekstraksi parameter tersebut tidak sejajar dengan kondisi manapun.

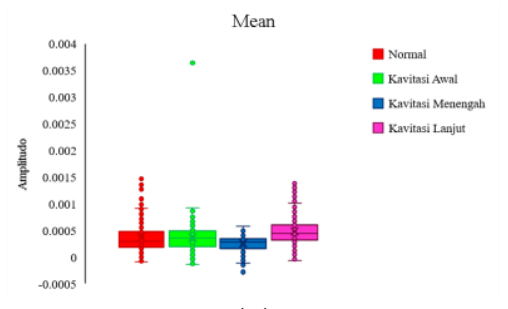

(a)

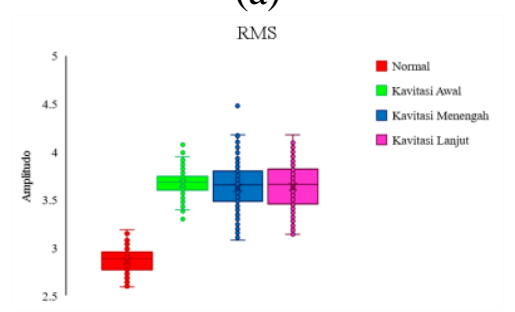

(b)

Gambar 5. Boxplot parameter (a) mean dan (b) RMS

Tabel 1. Analisis visual parameter statistik

\begin{tabular}{|c|c|}
\hline Parameter Statistik & Hasil Analisis Visual \\
\hline Mean & $\begin{array}{l}\text { Tidak dapat membedakan } \\
4 \text { variasi kondisi }\end{array}$ \\
\hline Standar deviasi & $\begin{array}{l}\text { Dapat membedakan } \\
\text { kondisi normal saja }\end{array}$ \\
\hline RMS & $\begin{array}{l}\text { Dapat membedakan } \\
\text { kondisi normal saja }\end{array}$ \\
\hline Kurtosis & \begin{tabular}{lrr} 
Dapat & \multicolumn{2}{c}{ membedakan } \\
kondisi normal dan \\
kavitasi menengah
\end{tabular} \\
\hline Skewness & $\begin{array}{l}\text { Tidak dapat membedakan } \\
4 \text { variasi kondisi }\end{array}$ \\
\hline Crest factor & $\begin{array}{l}\text { Tidak dapat membedakan } \\
4 \text { variasi kondisi }\end{array}$ \\
\hline Clearance factor & $\begin{array}{l}\text { Tidak dapat membedakan } \\
4 \text { variasi kondisi }\end{array}$ \\
\hline Shape factor & $\begin{array}{l}\text { Dapat membedakan } \\
\text { kondisi kavitasi awal dan } \\
\text { kavitasi lanjut }\end{array}$ \\
\hline Variance & \begin{tabular}{lrr} 
Dapat & \multicolumn{2}{c}{ membedakan } \\
kondisi normal dan \\
kavitasi menengah
\end{tabular} \\
\hline Peak value & $\begin{array}{l}\text { Dapat membedakan } \\
\text { kondisi kavitasi awal saja }\end{array}$ \\
\hline
\end{tabular}

Tabel 1 merupakan rangkuman hasil analisis secara visual dari distribusi nilai ekstraksi 10 parameter statistik. Hasil tersebut menunjukkan bahwa tidak ada parameter yang dapat membedakan 4 variasi secara keseluruhan.

Classifier LDA dilatih menggunakan 10 parameter statistik yang telah dibagi kedalam data training. Hasil dari pelatihan ini menghasilkan akurasi sebesar $98.8 \%$. Selanjutnya classifier LDA diuji akurasinya menggunakan data baru berupa data testing. Hasil pengujian ini menghasilkan akurasi sebesar 99,6\%. Gambar 6 merupakan confusion matrix dari hasil pelatihan dan pengujian.

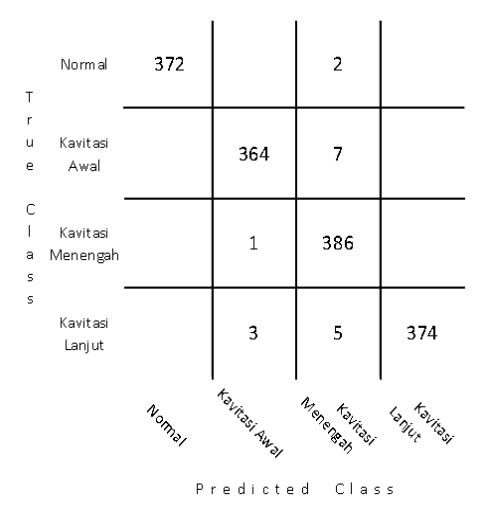

(a)

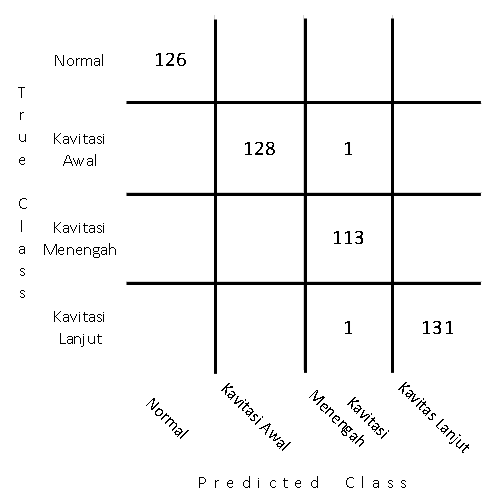

(b)

Gambar 6. Confusion matrix (a) data training dan (b) data testing

Hasil akurasi classifier LDA untuk mengklasfikasi kondisi pompa sangat baik dengan menggunakan 10 input parameter statistik. Namun demikian terdapat potensi parameter-parameter tersebut ada yang berkorelasi sehingga membawa informasi yang identik ataupun berkontribusi kecil dalam pembentukan classifier LDA. Maka, 
metode binomial coefficient digunakan pada penilitian ini untuk menemukan kombinasi parameter yang berkontribusi besar dalam classifier.

Kombinasi yang dibentuk yaitu mulai dari kombinasi 9 sampai dengan kombinasi 4 dari 10 parameter yang tersedia. Hasil kombinasi tersebut dapat dilihat pada Tabel 2 yang merupakan kombinasi yang menghasilkan akurasi tertinggi.

Tabel 2. Hasil tertinggi kombinasi 9 sampai

\begin{tabular}{|c|c|c|c|}
\hline \multirow{2}{*}{ Kombinasi } & \multirow{2}{*}{$\begin{array}{c}\text { Parameter } \\
\text { Statistik }\end{array}$} & \multicolumn{2}{|c|}{ Akurasi (\%) } \\
\hline & & Training & Testing \\
\hline 9 & $\begin{array}{l}\text { mean, RMS, } \\
\text { standar deviasi, } \\
\text { kurtosis, } \\
\text { skewness, crest } \\
\text { factor, } \\
\text { clearance } \\
\text { factor, shape } \\
\text { factor, dan } \\
\text { variance } \\
\end{array}$ & 99,1 & 99,8 \\
\hline 8 & $\begin{array}{l}\text { mean, RMS, } \\
\text { standar deviasi, } \\
\text { kurtosis, } \\
\text { skewness, crest } \\
\text { factor, } \\
\text { clearance } \\
\text { factor, dan } \\
\text { shape factor }\end{array}$ & 99,3 & 99,4 \\
\hline 7 & $\begin{array}{l}\text { mean, } \\
\text { RMS/standar } \\
\text { deviasi, kurtosis, } \\
\text { skewness, crest } \\
\text { factor, } \\
\text { clearance } \\
\text { factor, dan } \\
\text { shape factor }\end{array}$ & 99,4 & 99.4 \\
\hline 6 & $\begin{array}{l}\text { mean, } \\
\text { RMS/standar } \\
\text { deviasi, kurtosis, } \\
\text { skewness, crest } \\
\text { factor, dan } \\
\text { shape factor }\end{array}$ & 99,3 & 99,3 \\
\hline 5 & $\begin{array}{l}\text { mean, } \\
\text { RMS/standar } \\
\text { deviasi, kurtosis, } \\
\text { skewness, dan } \\
\text { shape factor }\end{array}$ & 99 & 99,4 \\
\hline 4 & $\begin{array}{l}\text { RMS/standar } \\
\text { deviasi, kurtosis, } \\
\text { skewness, dan } \\
\text { shape factor }\end{array}$ & 98,3 & 99 \\
\hline
\end{tabular}

Hasil tersebut dapat dilihat bahwa hasil tertinggi kombinasi 4 parameter merupakan parameter yang berkontribusi besar dalam classifier LDA. Hal ini dikarenakan hasil akurasi training yang didapat hanya selisih $0,5 \%$ dengan hasil akurasi training 10 input parameter.

Parameter RMS dan standar deviasi merupakan parameter yang membawa informasi yang sama besar kontribusinya karena dapat saling bertukar posisi dan menghasilkan akurasi training maupun testing yang sama besarnya. Hal ini dapat dilihat pada Tabel 2 dimulai dari kombinasi 7 hingga kombinasi 4 parameter.

\section{Kesimpulan}

LDA dengan input 10 parameter statistik terbukti dapat digunakan untuk mendeteksi dan mengklasifikasi terjadinya kavitasi pada berbagai variasi kondisi dengan akurasi training sebesar 98,8\% dan akurasi testing sebesar 99,6\%. Empat dari 10 parameter yang digunakan pada penelitian ini merupakan parameter yang paling berpengaruh pada akurasi classifier dalam mendeteksi kavitasi. Parameter tersebut yaitu RMS, kurtosis, skewness, dan shape factor. Hasil dari akurasi 4 parameter tersebut sebesar 98,3\% untuk training, sebesar $99 \%$ untuk testing. Standar deviasi merupakan parameter yang dapat bertukar posisi dengan RMS. Hal ini karena informasi yang terkandung dalam kedua parameter tersebut adalah informasi yang sama besar kontribusinya.

\section{Referensi}

[1] Tan, C.Z. and Leong, M.S., 2008. An Experimental Study of Cavitation Detection in a Centrifugal Pump Using Envelope Analysis. Journal of System Design and Dynamics, 274285.

[2] Kotb, A. and Abdulaziz, A. M., 2015. Cavitation Detection in Variable Speed Pump by Analyzing the Acoustic and Vibration Spectrums. Engineering, 706-716.

[3] Luo, Y., Sun, H., Yuan, S. and Yuan, J., 2015. Research on Statistical Characteristics of Vibration in Centrifugal Pump. Revista Tecnica de 
la Facultad de Ingenieria Universidad del Zulia, 49-61.

[4] Tobi, M. A. S. AL., and Sabari, M. H. J. Al., 2016. Cavitation Detection of Centrifugal Pump Using Time Domain Method. International Journal of Engineering Research and General Science, 161-167.

[5] Kamiel, B. P. and Ramadhan, R. S., 2017. Pengaruh Kecepatan Operasi Pompa Sentrifugal Terhadap Sensitifitas Metode Deteksi Fenomena Kavitasi Berbasis Parameter Statistik Domain Waktu," Semesta Teknika, 51-66.

[6] Tobi, M. A. S. AL., Bevan, G., Wallace, P., Harrison, D. and Ramachandran, K. P., 2019. Centrifugal Pump Condition Monitoring and Diagnosis Using Frequency Domain Analysis. Int. Conf. Cond. Monit. Mach. NonStationary Oper., 122-131.

[7] Kamiel, B. P., Wiranto, A. J., Riyanta, B. and Yulianto, S., 2019. Klasifikasi Cacat Lintasan Dalam Bantalan Bola Berbasis Support Vector Machine (SVM) pada Fan Industri. Turbo, 143152.

[8] Sharma, P. and Kaur, M., 2013. Classification in Pattern Recognition: A Review. Int. J. Adv. Res. Comput. Sci. Softw. Eng., 298-306.

[9] Jakovljevic, B. B., Kanovic, Z. S. and Jelicic, Z. D., 2012. Induction Motor Broken Bar Detection Using Vibration Signal Analysis, Principal Component Analysis and Linear Discriminant Analysis. Proc. IEEE Int. Conf. Control Appl., 1686-1690.

[10] Haddad, R. Z., and Strangas, E. G., 2016. On the Accuracy of Fault Detection and Separation in Permanent Magnet Synchronous Machines Using MCSA/MVSA and LDA. IEEE Trans. Energy Convers., 924-934.

[11] Mbo'o, C. P. and Hameyer, K., 2016. Fault Diagnosis of Bearing Damage by Means of the Linear Discriminant Analysis of Stator Current Features from the Frequency Selection. IEEE Trans. Ind. Appl., 3861-3868.

[12] Nandi, A. and Ahmed, H., 2019. Condition Monitoring with Vibration Signals. Brunel University London, UK. 